\title{
MATHEMATICAL READINESS ASSESSMENT FOR FIRST-YEAR STUDENTS
}

\author{
Janina Kaminskiene ${ }^{1}$, Daiva Rimkuviene ${ }^{1}$, \& Eve Aruvee $^{2}$ \\ ${ }^{1}$ Vytautas Magnus University (Lithuania) \\ ${ }^{2}$ Estonian University of Life Sciences (Estonia)
}

\begin{abstract}
Critical thinking, problem-solving skills and general mathematical competency are necessary for many occupations today. While working with first-year students, varying competence and confidence in mathematics is observed. This paper discusses the use of common mathematical diagnostic tests for the evaluation mathematical preparedness of the first-year students. The test was compiled by an international team of mathematicians and organised for the first time in the autumn of 2000 in the cooperating agricultural universities in Latvia, Sweden, Estonia and Lithuania. The test consists of 15 tasks and focuses on fundamental mathematical concepts and helps identify students' mathematical strengths and weaknesses. Various secondary and tertiary education reforms raise new challenges for universities mathematicians. Diagnostic tests provide the possibility to identify tasks that are more problematic for students and also allow to compare the competence of first-year students' mathematics competence between the different universities.

A graphical analysis method and a method of statistical quantitative analysis of the research data were used in the study. The results of the research revealed a connection between the students' mathematical preparedness and ongoing educational reforms. The results of this test also reveal a contradiction between quantity and quality in studies. Measures to improve the learning process of the subject of Mathematics depending on the level of students' ability are offered.
\end{abstract}

Keywords: Mathematics, diagnostic test, mathematical preparedness, mathematical competence.

\section{Introduction}

Mathematics is one of the most essential components of general education for students. The evaluation of mathematics as a subject at school is involved in the calculation of the entrance score to all technical and economic specialties at our university. However, the level of knowledge between each student who enters the university is rather different and usually, it differs from the grade received at school (Rimkuviene D., Kaminskiene J., \& Laurinavičius E. (2011)). Lower knowledge in mathematics means a slower understanding and learning of mathematics at university. Universities can play a major role to address the concern by providing the necessary academic support services for students who are considered academically underprepared (Atuahene, F., \& Russell, T. A. (2016)).

The object of the research is the mathematical test results of the first-year agriculture students in Lithuania and Estonia.

The aim of the research is to analyse and evaluate the changes in mathematical readiness of the first-year agriculture students.

\section{Education reforms and mathematical competences}

Education reforms happening in Lithuania influence the level of students' mathematical readiness. Learning mathematics in two different difficulty levels - A (expanded course) and B (general course) - creates different backgrounds for mathematical readiness. Having studied B level mathematics without taking the mathematics state exam, young people usually have difficulties in learning mathematics at the university.

On one hand, free market and competition at university studies (new studies with own funds and an unlimited number of new students) gave an opportunity for more young people to study; on the other hand, this allowed the students with low levels of readiness to enter universities, too. Universities left the problem of under-prepared students to the lecturers who are teaching the subject. 


\section{Participants, data collection and analysis}

From 2000 to 2018, the mathematical readiness test was attended by Vytautas Magnus University Agricultural Academy first-year students during their first week at the university (in total, 6347 students). Test results received from students of class 2018 from Estonian University of Life Sciences were used as a comparison (226 students). The test in both countries was the same.

The test contains 15 tasks. Each task has 4 options. After solving the task in the draft, students have to mark only one correct answer. The test lasts 45 minutes. No formulas or calculators are used. The tasks are comprised of short problems and different topics needed later at university. The results of these tests are used to analyse students' mathematical readiness. Each student's scores are noted, the results from different specialties and groups are calculated.

\section{Results}

By analysing test results from the period of 19 years, we can notice the periods of time when average results grow and decline (Figure 1).

Figure 1. The average score of the common-math test (Agricultural Academy).

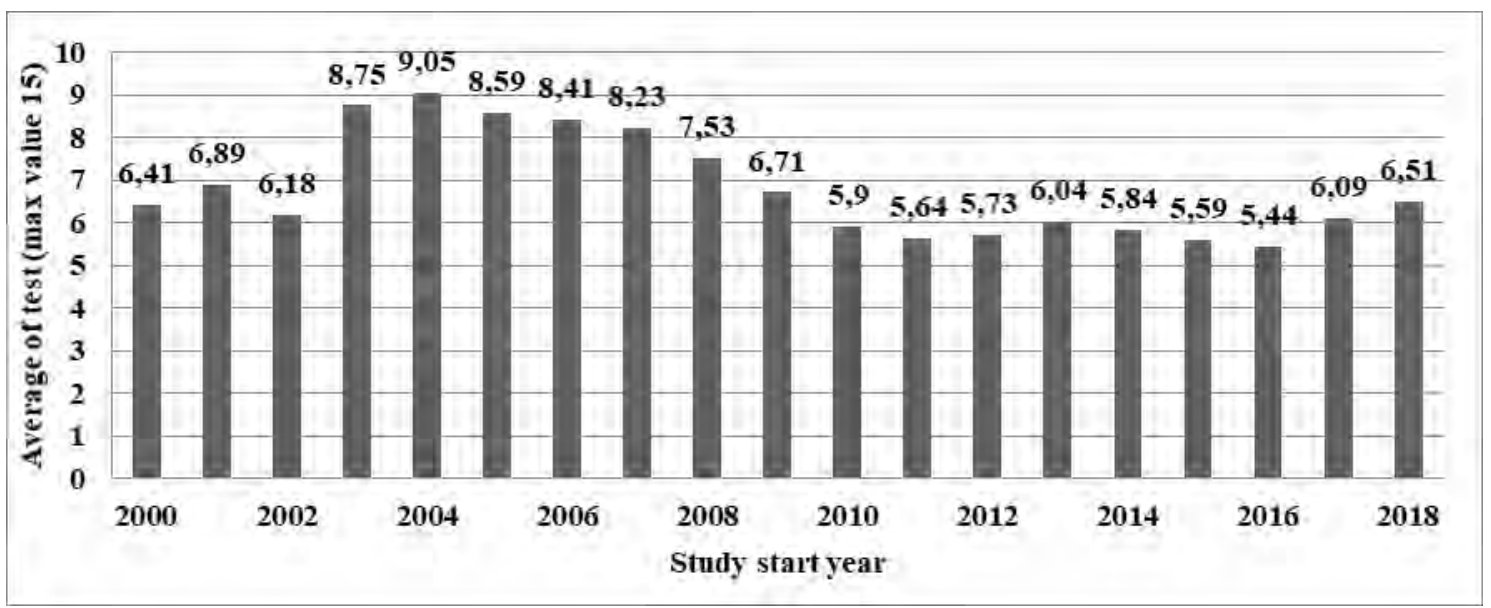

For a long time, mathematical readiness was assessed according to the results of school-leaving exams (10-point scale, taken in schools). Since 1999, a state exam of Mathematics is introduced and chosen (100-point scale, taken in exam centres). The examination reform in Lithuania was successful so the results of the state exam had a more significant value while entering universities; it is shown by our test results, too. Until 2008, universities had a limited amount of new students which was decided by state funding. A contest was held to enter most of the specialties. When the competition between universities was allowed and the number of new students increased, huge differences between mathematical readiness of new students appeared. The average test results started declining and they remained low until 2016.

The mathematicians of the Agricultural Academy apply a number of methods to teach mathematics:

- Under-prepared students are suggested to take mathematics review courses;

- Methodological literature are prepared based on the specialty's programme; these methodological means in detail explain the methods and processes of solving tasks and they help to review the basic mathematics knowledge from school;

- Detailed learning material with self-control tests and video footage are created in Moodle;

- During practical work, a method of mini-tests is used;

- Each week, lecturers devote some extra time (3 academic hours) to student consultations.

Some methods were successful (Moodle, mini-tests) but others not so much (mathematics review courses). Students do not really use personal consultations, often it is used just before tests or exams.

The common diagnostic test allows comparing the level of readiness between the students from different countries. While testing the null hypothesis, we found that there is no significant difference between the means of the Estonian student's test and the Lithuanian student's test ( $p$-value=0.14). However, the results of knowledge acquisition differed. Figure 2 and 3 present the compared results between separate tasks. 
Figure 2. Tasks at which the Estonian students performed better.

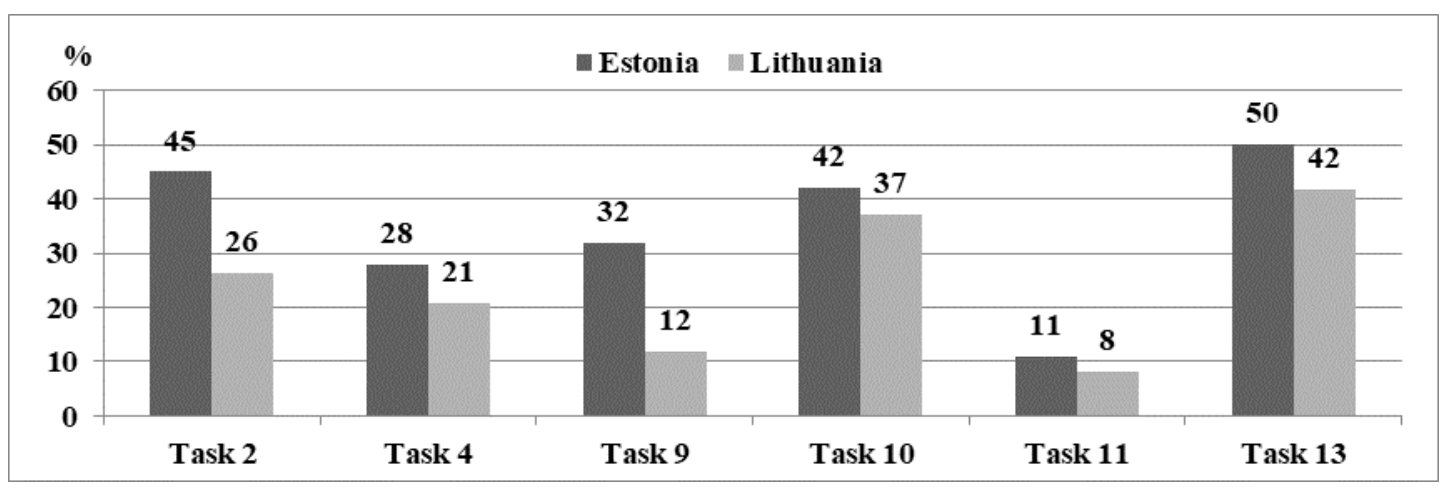

The Estonian students had a better performance at 6 tasks out of 15 . The following tasks were done significantly better by Estonian students: trigonometry (Task 9), algebra (Task 2) and the percent word problem (Task 13). Students from both countries didn't know square root properties (Task 11).

Figure 3. Tasks at which the Lithuanian students performed better.

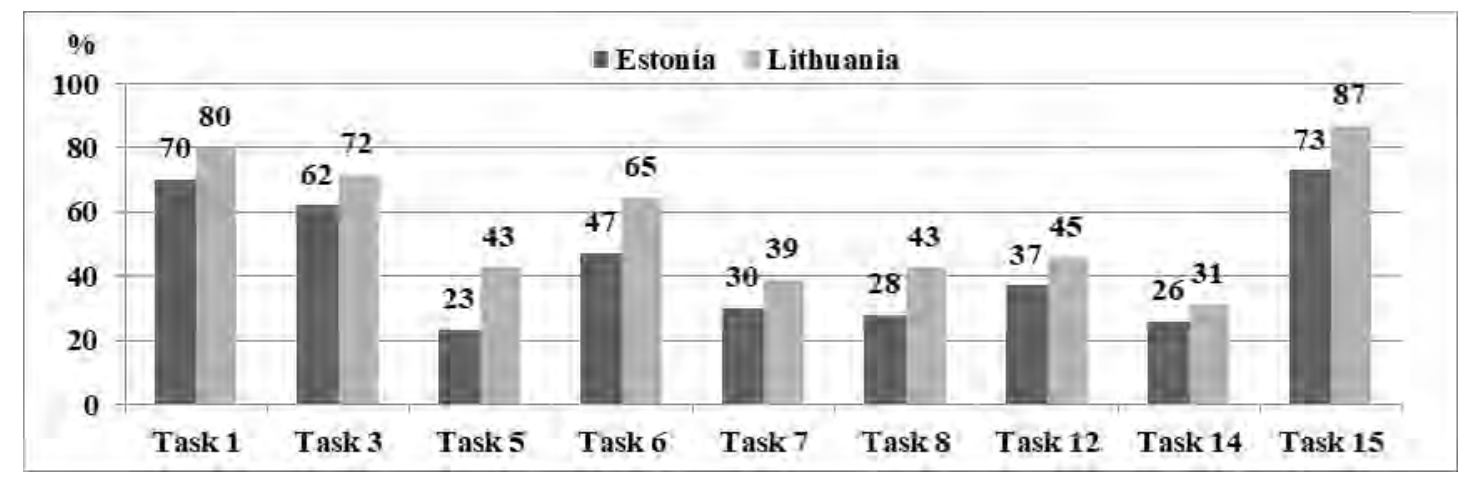

Figure 3 shows that the Lithuanian students had a better performance at 9 tasks out of 15 . The following tasks were done significantly better: the task with logarithm (Task 5), the task where students had to find reverse function (Task 6) and the task where students had to solve a square equation (Task 8). Students from both countries are equally good at solving the tasks with fractions (Task 1) and the Pythagorean Theorem (Task 15). The solving percent of most tasks is either equally good or equally bad. Some subjects like tasks with square root properties (Task 11) or algebra tasks (Task 14) are understood equally bad by the students from both countries.

\section{Conclusions}

The test results show that a part of new university students have bad mathematical readiness (more than half of the students couldn't solve most of the tasks). The more students, the bigger is the number of students who are under-prepared. Thus, the quantity means lesser quality and we are faced with certain challenges while teaching mathematics. Since the number of school and gymnasium graduates is decreasing (since 2011), the number of students in universities is decreasing, too. In the recent year, universities are requiring a cumulative score which largely consists of a score from the mathematics state exam; therefore, we are noticing slightly better results which are still not enough. The comparison between the Estonian and Lithuanian test results encourages doing a more detailed comparative analysis of learning programmes in schools.

\section{References}

Atuahene, F., \& Russell, T. A. (2016). Mathematics readiness of first-year university students. Journal of Developmental Education, 39(3), 12-20.

Rimkuviene D., Kaminskiene J., \& Laurinavičius E. (2011) Teaching mathematics at the Faculty of Economics and Management. Economic Science for Rural Development: Proceedings of the International Scientific Conference: Resources and Education. Latvia: Jelgava, 25, 231-237. 